\title{
Eumelanin-based coloration and fitness parameters in birds: a meta-analysis
}

Behavioral Ecology and Sociobiology

ISSN 0340-5443

Volume 65

Number 4

Behav Ecol Sociobiol (2011) 65:559-567

DOI 10.1007/s00265-010-1092z

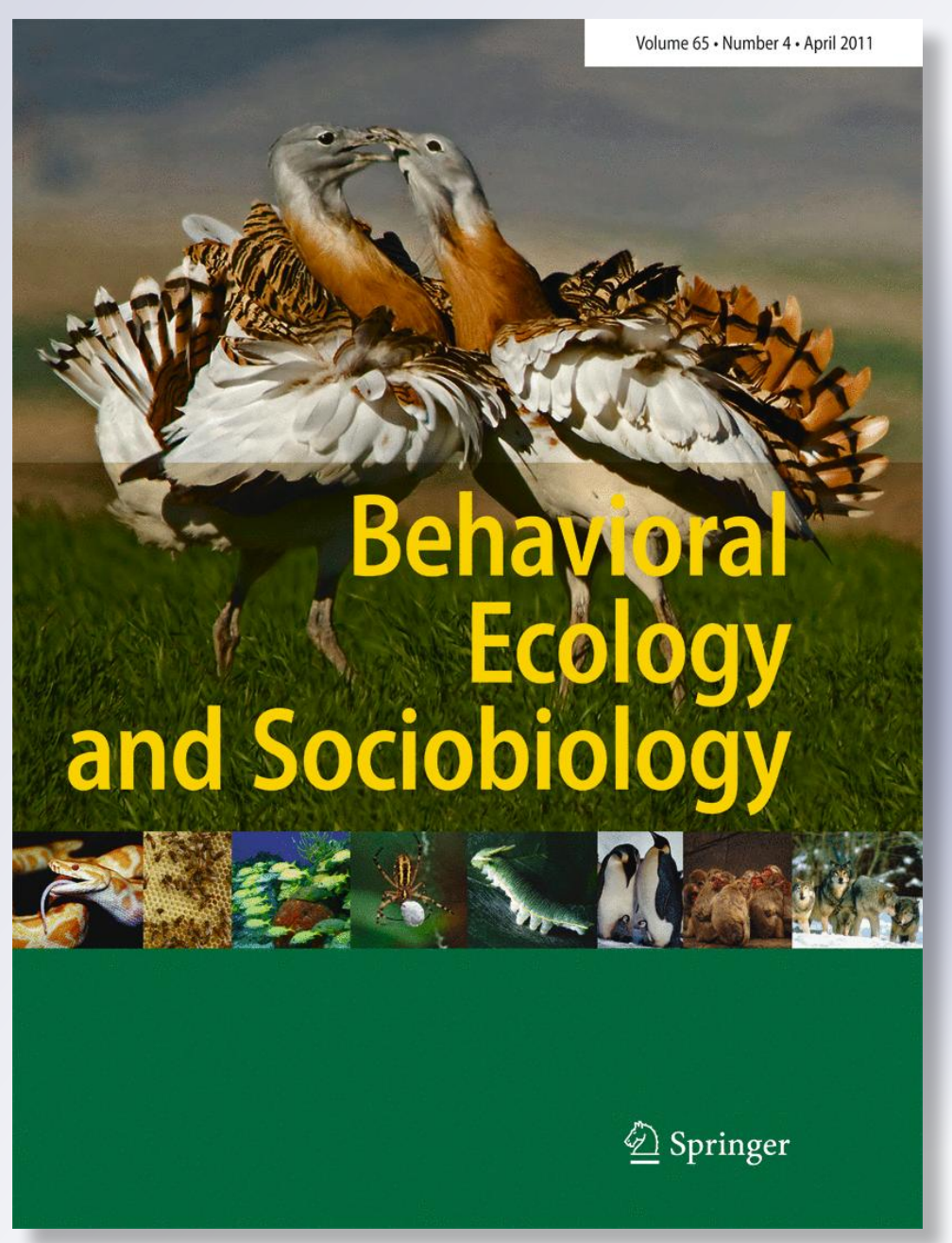

勿 Springer 
Your article is protected by copyright and all rights are held exclusively by SpringerVerlag. This e-offprint is for personal use only and shall not be self-archived in electronic repositories. If you wish to self-archive your work, please use the accepted author's version for posting to your own website or your institution's repository. You may further deposit the accepted author's version on a funder's repository at a funder's request, provided it is not made publicly available until 12 months after publication. 


\title{
Eumelanin-based coloration and fitness parameters in birds: a meta-analysis
}

\author{
Joël Meunier • Susana Figueiredo Pinto • Reto Burri • \\ Alexandre Roulin
}

Received: 6 August 2010 /Revised: 5 October 2010 /Accepted: 19 October 2010 /Published online: 3 November 2010

(C) Springer-Verlag 2010

\begin{abstract}
Although melanin is the most common pigment in animal integuments, the adaptive function of variation in melanin-based coloration remains poorly understood. The individual fitness returns associated with melanin pigments can be variable across species as these pigments can have physical and biological protective properties and genes involved in melanogenesis may vary in the intensity of pleiotropic effects. Moreover, dark and pale coloration can also enhance camouflage in alternative habitats and melanin-based coloration can be involved in social interactions. We investigated whether darker or paler individuals achieve a higher fitness in birds, a taxon wherein associations between melanin-based coloration and fitness parameters have been studied in a large number of species. A meta-analysis showed that the degree of melanin-based coloration was not significantly associated with laying date, clutch size, brood size, and survival across 26 species. Similar results were found when restricting the analyses to non-sexually dimorphic birds, colour polymorphic and monomorphic species, in passerines and non-passerines and in species for which inter-individual variation in melanism is due to colour intensity. However, eumelanic
\end{abstract}

Communicated by K. McGraw

J. Meunier and S. Figueiredo Pinto contributed equally to this paper.

Electronic supplementary material The online version of this article (doi:10.1007/s00265-010-1092-z) contains supplementary material, which is available to authorized users.

J. Meunier $\cdot$ S. Figueiredo Pinto $\cdot$ R. Burri $\cdot$ A. Roulin $(\bowtie)$ Department of Ecology and Evolution, University of Lausanne, 1015 Lausanne, Switzerland

e-mail: Alexandre.Roulin@unil.ch

J. Meunier

Zoological Institute, Evolutionary Biology, University of Basel, 4056 Basel, Switzerland coloration was positively associated with clutch and brood size in sexually dimorphic species and those that vary in the size of black patches, respectively. Given that greater extent of melanin-based coloration was positively associated with reproductive parameters and survival in some species but negatively in other species, we conclude that in birds the sign and magnitude of selection exerted on melanin-based coloration is species- or trait-specific.

Keywords Condition-dependent · Fitness · Melanin-based coloration $\cdot$ Meta-analysis $\cdot$ Natural and sexual selection

\section{Introduction}

In both vertebrates and invertebrates melanin is the pigment that is most frequently used in the integument and either gives blackish (eumelanins) or reddish colorations (pheomelanins). Melanins are more frequently used than carotenoids or porphyrin probably because they have multiple key functions. Melanins have physical and biological properties that enhance resistance to abrasion of the external body surface (Bonser 1995; Burtt 1979) and that protect against solar radiation (Clusella Trullas et al. 2007), oxidative stress (McGraw 2005) and pathogens (Mackintosh 2001). Genes involved in melanogenesis can have numerous pleiotropic effects on other phenotypic traits implying that coloration can evolve as an indirect response to selection exerted on genetically correlated traits (Ducrest et al. 2008; Galván and Alonso-Alvarez 2008). Finally, melanin-based coloration itself can play a role in foraging (Galeotti and Sacchi 2003; Roulin and Wink 2004) and anti-predatory strategies (Jones et al. 1977; Johannesson and Ekendahl 2002), for instance, by improving camouflage (Hoekstra et al. 2005). 
In many animals, individuals from the same population vary in the degree of melanin-based coloration. In genetically colour-polymorphic species the evolutionary stability of colour variation requires that alternative dark and pale melanic morphs achieve the same fitness in the long term (Losey et al. 1997; Bond and Kamil 1998; Roulin 2004). In contrast, in species in which melanin-based coloration evolved under directional sexual selection, dark individuals may be superior to paler conspecifics if the expression of melanin-based coloration has a significant conditiondependent component. Assuming that the production of melanic coloration entails significant costs, only the best individuals could afford to produce the darkest version of a colour trait. Evidence for a trade-off between resource allocation in melanin-based sexually selected traits and other physiological processes such as immunocompetence and resistance to oxidative stress has been confirmed in some species (Fitze and Richner 2002; Horth 2003; Fargallo et al. 2007; Roulin et al. 2008) but not in others (Bize et al. 2006; Buchanan et al. 2001; McGraw and Hill 2000; McGraw et al. 2002; Roulin et al. 1998; Siefferman and Hill 2005). Thus, the level of condition-dependent expression of melanin-based coloration may vary across species and between traits. Furthermore, in some species white rather than black coloration reflects quality (e.g. Hanssen et al. 2006), suggesting that sometimes pale coloration is more costly to produce than dark coloration (Hanssen et al. 2008). As a consequence, the signalling function of melanin-based traits remains controversial. This situation is further complicated by the fact that within a given species different melanin-based colour traits may have various functions with some specific parts of the body or some specific colour traits being sexually selected and others naturally selected. Thus, ideally more than one melanin-based trait should be considered in the studied species, an approach that is rarely considered.

If selection exerted on melanic coloration is species-, population- or trait-specific, the degree of coloration may not be correlated with fitness components in any consistent way across vertebrates. We tested this by performing metaanalyses of studies on melanism and fitness carried out in birds and while controlling for phylogeny. We considered birds because they represent the only taxon with a sufficiently large number of published papers on the relationship between melanin-based coloration and fitness parameters, i.e. laying date, clutch and brood sizes as well as survival. Because selection exerted on coloration is likely to differ in both sign and magnitude between genders or group of species, we performed one global and several specific meta-analyses, so-called meta-regression (Borenstein et al. 2009), on different subsets of the data. Since the intensity of sexual and natural selection probably differs between males and females, a first group of meta-analyses was performed on data sets including only males and then only females. Then, we investigated whether covariation between fitness components and melanin-based coloration differs between sexually dimorphic and non-dimorphic species, because sexual dimorphism is usually thought to be the result of directional sexual selection. We performed separate analyses in passerines versus non-passerines because passerines are traditionally used in sexual selection studies. We also considered colour polymorphic versus monomorphic species, because in colour polymorphic species dark and pale individuals are predicted to achieve the same fitness (Roulin 2004), whereas in monomorphic species coloration may be associated with fitness parameters. Finally, we conducted separate analyses in species where colour traits vary between individuals in their size versus colour intensity. We restricted our meta-analyses to eumelaninbased coloration (i.e. black and grey coloration) because few studies have yet been published on pheomelaninbased coloration (i.e. reddish-brown coloration).

\section{Material and methods}

\section{Data collection}

We performed a large-scale search of studies that tested the above predictions using a number of methods. In particular, we (1) used an extensive collection of studies on melaninbased traits gathered for the last 10 years, (2) searched for recent articles containing the keywords 'melanin' or 'melanism' in the Web of Science considering publications until 12 July 2010, and finally (3) looked for citations in reviews of the subject (Ducrest et al. 2008; Jawor and Breitwisch 2003; Nakagawa et al. 2007; Roulin 2004) and in all papers found using the above methods. We did not include in the meta-analyses studies for which effect sizes could not be calculated because raw data were not available as well as appropriate statistical analyses (e.g. Bókony et al. 2008; Cooke et al. 1995; Hatch 1991; Roulin and Altwegg 2007; Roulin et al. 2003). Finally, data on the tawny owl (Strix aluco), barn owl (Tyto alba) and Alpine swift (Apus melba) were obtained from our own unpublished data. Although tawny owls vary in the degree of reddishness, Gasparini et al. (2009) showed that feathers of redder individuals contain more eumelanin than feathers of pale conspecifics. We included 28 published studies and four unpublished data sets in the meta-analyses on reproductive parameters and 15 studies on survival. For most of the species used in the present study, the authors mentioned that melanin-based coloration plays a role in mate choice (e.g. Mundy et al. 2004). Thus, melanin-based traits considered may not be neutral to both sexual and natural selection. Because the data set on adult survival was not available for 
both males and females, we did not investigate sex differences in effect sizes in the survival analyses. Additionally, we report the sign of the relationship between adult survival and melanin-based coloration for the studies not included in the meta-analysis. The data used to carry out the metaanalyses are reported in the Online Resource 1.

\section{Meta-analyses}

For each study, sign and magnitude of the correlation between melanin-based coloration and laying date, clutch size, brood size and survival were given by the parameter 'effect size' $r$ calculated following standard methodology (Rosenthal 1991). We defined a positive effect size when individuals with larger or darker melanin-based colour traits had lower laying date, had larger clutch size, larger brood size and higher survival rate than individuals with smaller or paler melanin-based colour traits. When authors provided Spearman's rank or Pearson's correlations, theses values were directly used as effect sizes. In other cases, effect sizes were calculated from the available statistics (e.g. $t, x^{2}, F, Z$, $r^{2}, P$ values) and sample sizes using standard formulas (Rosenthal 1991). When statistics were derived from analyses of variance (ANOVA) with more than two treatments, we applied an ordered heterogeneity $(\mathrm{OH})$ test (Rice and Gaines 1994a, b). For the few studies where values of statistical analyses were missing or could not be used (Online Resource 1), we recalculated appropriate statistics using raw data reported in the text, tables or figures using standard formulas and R.2.9.2 (Sokal and Rohlf 1995).

Mean effect sizes and homogeneity of effect sizes within data sets were estimated using the software phyloMeta v1.0beta (http://lajeunesse.nescent.org/software.html). This software accounts for potential phylogenetic bias in a data set by performing meta-analyses wherein effect sizes are weighted by the phylogenetic relationships of the studied species towards the species included in the analysis (Lajeunesse 2009). Effect sizes entered into the metaanalyses were previously transformed into $Z r$ values to correct for asymptotic behaviour of large values of $r$ (Rosenberg et al. 2000; Sheldon and West 2004). We considered one mean $Z r$ value per species and fitness component (i.e. laying date, clutch size, brood size and survival). When the same species was studied in several populations, over several years, or for females and males separately, we calculated an average $Z r$ value weighted by sample size as usually done in meta-analyses (West et al. 2005). Sample sizes were summed when studies were conducted on different populations but averaged when a single study reported several statistics from the same populations (e.g. if a study was carried out in several years). Meta-analyses were computed using random effect models (Møller and Jennions 2002; Rosenberg et al. 2000;
Rosenthal 1991; West et al. 2005). Results were backtransformed into $r$ values for illustrative purposes.

We calculated the homogeneity of effects sizes $Q_{\mathrm{H}}$ to determine whether sampling error can explain the observed variation among our collection of effect sizes (Lajeunesse 2009). In particular, significant $Q_{\mathrm{H}}$ indicated that a relationship between eumelanin-based coloration and fitness was heterogeneous across species or a group of species. In this case, four moderator variables (i.e. sexual dimorphism, colour polymorphism, passerine vs. non-passerine and intensity vs. patch size of melanism) were successively used as grouping variables in a new meta-analysis, so-called metaregression (Lajeunesse 2009). We also performed two separate meta-analyses on male and female data sets, as effect sizes may differ between sexes from similar species (see Online Resource 1). Differences between sub-classes (i.e. males vs. females, sexual mono- vs. dimorphism, colour mono- vs. polymorphism, passerine vs. not passerine, and eumelanism intensity with size vs. colour) were considered as significant when $95 \%$ confidence intervals did not overlap. Since seven meta-analyses were conducted on the same data set, type I errors due to multiple testing were controlled using Bonferonni correction, wherein criterion $\alpha=0.05$ was transformed to $\alpha=0.007$ (i.e. all the reported $P$ values are uncorrected and considered significant when smaller than 0.007). Finally, models with and without moderator variables were compared using AIC criterion to determine which moderator better fits our data set (Lajeunesse 2009).

The tree topology used to correct for phylogenetic signals was compiled from previous studies. The relationships among orders and families were extracted from recent avian phylogenies (Brown et al. 2007; Ericson et al. 2006; Hackett et al. 2008), and relationships within orders and families were retrieved from phylogenetic studies conducted in the respective taxa (Alström et al. 2006; Fain and Houde 2004; Johansson et al. 2008; Kimball and Braun 2008; Lovette and Bermingham 2002; Treplin et al. 2008). To estimate branch lengths, cytochrome $b$ sequences were retrieved from the GenBank database for each species with available data. When data were not available for a species, we used data from a congener (Anser albifrons, Phalacrocorax pelagicus, Poecile rufescens; Online Resource 2). Sequences were aligned using the ClustalW algorithm (Thompson et al. 1994). We used 921 bp to estimate branch lengths for the tree encompassing all species included in this study using PAUP 4 beta 10 (Swofford 2003) based on a GTR $+\mathrm{I}+\mathrm{G}$ model of nucleotide substitution. Based on this tree, ultrametric branch lengths were obtained using the pelanized likelihood approach by Sanderson (2002) implemented in the ape package (Paradis et al. 2004) in the software R 2.9.2. Subtrees for each trait were obtained by pruning species for which no measure- 
ments were available in Mesquite 2.71 (Maddison and Maddison 2009). The species tree considered in the present study can be found in Online Resource 2.

We used different methods to detect potential publication bias, which can arise if the likelihood of publishing results depends on the strength or direction (negative or positive correlation) of scientific findings. First, we used 'funnel plot' method to graph effect sizes against sample sizes (Møller and Jennions 2001). In the absence of publication bias, we expect a funnel shape due to a decrease in sample error with increased sampling effort. But in the presence of publication bias, we expect significant negative or positive correlations between effect sizes and sample sizes due to a deficit of studies with effect sizes smaller or bigger than the true effect size, respectively. The strength and direction of the publication bias can then be quantitatively assessed using a Spearman's rank correlation. Second, we evaluated the potential consequences of publication bias on our results using the 'trim and fill' method (Rosenthal 1991). This method estimates the number $\left(L_{0}\right)$ of 'missing' unpublished studies in our data set due to publication bias, simulates them and adds them to the data set in order to recalculate a corrected effect size and its significance (Møller and Jennions 2001).

\section{Results}

Across bird species, the mean effect sizes for the relationship between eumelanin-based coloration and laying date, clutch size, brood size and survival were not significantly different from zero (Table 1). By contrast, tests for homogeneity among effect sizes revealed significant results (Table 1), suggesting that associations between eumelaninbased coloration and fitness parameters varies among species. Therefore, we determined the effect of potential moderator variables.

In general, mean effect sizes remained non-significant when data sets were analyzed in relation to sex or using moderators including sexual dimorphism, colour polymorphism, membership to the Passeriformes order or type of colour trait (Table 1). We found only two significant effects: in sexually dimorphic species darker eumelanic individuals produced more eggs, and in species for which colour traits vary in size individuals displaying larger black patches produced more young. Moreover, the association between eumelanin-based coloration and clutch size was significantly larger in sexually dimorphic than sexually monomorphic species further suggesting that in sexually dimorphic birds dark coloration is directionally selected (Table 1). For all other data sets, confidence intervals of the mean effects sizes overlapped between males and females, sexually dimorphic and non-dimorphic species, colour polymorphic and monomorphic species, Passeriformes and non-Passeriformes species, as well as between species for which colour traits vary in size versus those which vary in colour intensity (Table 1). Finally, the use of moderators only slightly improved AIC values and effect sizes remained significantly heterogeneous within most of the data sets (Table 1). This indicates that associations between eumelanin-based coloration and fitness parameters are species- or trait-specific.

Overall, only the data set on brood size presented publication bias. In particular, sample sizes were significantly correlated with mean effect sizes in the global data set (Fig. 1, $r_{\mathrm{s}}=-0.69, P=0.001$ ), as well as on the ones focusing on males $\left(r_{\mathrm{s}}=-0.72, P=0.002\right)$, sexually dimorphic species $\left(r_{\mathrm{s}}=-0.77, P=0.003\right)$, colour monomorphic species $\left(r_{\mathrm{s}}=-0.77, P=0.012\right)$, Passeriformes species $\left(r_{\mathrm{s}}=-0.40, P=\right.$ 0.012 ) and species that vary in the intensity of black patches $\left(r_{\mathrm{s}}=-0.63, P=0.018\right)$. This bias tends to overestimate the corresponding mean effect sizes since significant correlations between brood size and melanin-based traits were more likely to be published when based on small than large data sets. However, the non-significant results remained robust as trim and fill method indicates that additional studies that might be necessary to correct for publication bias would not change the non-significance of these mean effect sizes (for all data sets with non-significant results: $L_{0}=$ between 1 and 7; adjusted mean $r=$ between -0.009 and 0.067; all $P>0.05$ ). For all other data sets used in the metaanalyses, correlations between sample sizes and effect sizes were not significant (Fig. 1, all $P>0.08$ ).

\section{Discussion}

In meta-analyses controlling for phylogeny, we found that across bird species variation in melanin-based coloration was not significantly associated with laying date, clutch size, brood size and survival. In some species the degree of coloration was positively correlated with reproductive and survival parameters, while in other species the opposite pattern was detected (Table 1 and Online Resource 1). We nevertheless found that in sexually dimorphic species and in species for which melanic trait varies in size rather than in colour intensity between individuals, clutch size and brood size covaried positively with the degree of melaninbased coloration. Thus, greater extent of melanin-based coloration reflects absolute individual quality (i.e. fitness components) in some species, particularly in sexually dimorphic species (e.g. Roulin et al. 2010) and in those that vary in the size of black patches (e.g. Jensen et al. 2004), while a lightly coloured plumage can sometimes signal absolute quality in other species (e.g. Schroeder et al. 2009). 
Table 1 Mean effect sizes $(r)$ and homogeneity of effect sizes $\left(Q_{\mathrm{H}}\right)$ of studies investigating the relationship between eumelanin-based coloration and laying date, clutch size, brood size and survival in birds

\begin{tabular}{|c|c|c|c|c|c|c|c|c|c|c|c|}
\hline & \multirow[b]{2}{*}{ Global } & \multicolumn{2}{|l|}{ Sex } & \multicolumn{2}{|c|}{ Sexual dimorphism } & \multicolumn{2}{|c|}{ Colour polymorphism } & \multicolumn{2}{|c|}{ Passerine } & \multicolumn{2}{|c|}{ Eumelanism intensity } \\
\hline & & Males & Females & Yes & No & Yes & No & Yes & No & Size & Color \\
\hline \multicolumn{12}{|l|}{ Brood size } \\
\hline No. of species & 19 & 17 & 7 & 13 & 6 & 7 & 12 & 11 & 8 & 14 & 5 \\
\hline Mean effect size $(r)$ & -0.011 & -0.024 & 0.043 & -0.024 & 0.044 & 0.001 & 0.017 & 0.017 & 0.021 & 0.144 & 0.047 \\
\hline Lower $95 \% \mathrm{CI}$ & -0.088 & -0.112 & -0.041 & -0.105 & -0.050 & -0.068 & -0.071 & -0.075 & -0.064 & 0.070 & -0.057 \\
\hline Upper $95 \% \mathrm{CI}$ & 0.065 & 0.065 & 0.124 & 0.056 & 0.137 & 0.070 & 0.106 & 0.108 & 0.107 & 0.217 & 0.150 \\
\hline$Z$ value & 0.08 & 0.28 & 1.01 & 0.33 & 0.85 & 0.00 & 0.15 & 0.13 & 0.24 & 14.29 & 0.79 \\
\hline$P$ value & 0.774 & 0.598 & 0.314 & 0.564 & 0.357 & 0.980 & 0.700 & 0.720 & 0.624 & $<0.001$ & 0.375 \\
\hline Homogeneity $\left(Q_{H}\right)$ & 46.64 & 47.73 & 8.93 & 32.37 & 6.81 & 11.74 & 35.84 & 29.14 & 17.95 & 120.04 & 6.22 \\
\hline$P$ value & $<0.001$ & $<0.001$ & 0.178 & 0.001 & 0.235 & 0.068 & $<0.001$ & 0.001 & 0.012 & $<0.001$ & 0.183 \\
\hline model AIC & 67.84 & 61.62 & 25.57 & 66.36 & & 70.35 & & 65.82 & & 66.44 & \\
\hline \multicolumn{12}{|l|}{ Clutch size } \\
\hline No. of species & 15 & 10 & 7 & 10 & 5 & 4 & 11 & 6 & 9 & 10 & 5 \\
\hline Mean effect size $(r)$ & 0.059 & 0.010 & 0.022 & 0.195 & -0.016 & -0.005 & 0.083 & 0.176 & 0.060 & 0.082 & 0.054 \\
\hline Lower 95\% CI & -0.028 & -0.133 & -0.054 & 0.086 & -0.087 & -0.130 & -0.030 & 0.039 & -0.016 & -0.037 & -0.062 \\
\hline Upper $95 \% \mathrm{CI}$ & 0.144 & 0.153 & 0.097 & 0.299 & 0.055 & 0.119 & 0.195 & 0.307 & 0.135 & 0.198 & 0.171 \\
\hline$Z$ value & 1.76 & 0.02 & 0.32 & 12.16 & 0.19 & 0.01 & 2.07 & 6.31 & 2.40 & 1.81 & 0.84 \\
\hline$P$ value & 0.185 & 0.890 & 0.575 & 0.001 & 0.662 & 0.940 & 0.151 & 0.012 & 0.121 & 0.178 & 0.361 \\
\hline Homogeneity $\left(Q_{\mathrm{H}}\right)$ & 54.87 & 41.19 & 10.29 & 33.55 & 14.87 & 3.25 & 45.52 & 14.74 & 37.10 & 36.22 & 8.57 \\
\hline$P$ value & $<0.001$ & $<0.001$ & 0.113 & $<0.001$ & 0.005 & 0.355 & $<0.001$ & 0.012 & $<0.001$ & $<0.001$ & 0.073 \\
\hline model AIC & 57.88 & 36.24 & 26.56 & 56.82 & & 54.62 & & 58.25 & & 53.61 & \\
\hline \multicolumn{12}{|l|}{ Laying date } \\
\hline No. of species & 14 & 11 & 7 & 8 & 6 & 5 & 9 & 5 & 9 & 8 & 6 \\
\hline Mean effect size $(r)$ & 0.065 & 0.033 & 0.078 & 0.043 & 0.099 & 0.055 & 0.069 & 0.038 & 0.068 & 0.046 & 0.097 \\
\hline Lower $95 \% \mathrm{CI}$ & -0.043 & -0.102 & -0.041 & -0.067 & 0.001 & -0.063 & -0.038 & -0.106 & -0.020 & -0.055 & -0.007 \\
\hline Upper $95 \% \mathrm{CI}$ & 0.171 & 0.166 & 0.194 & 0.153 & 0.194 & 0.172 & 0.174 & 0.179 & 0.154 & 0.144 & 0.196 \\
\hline$Z$ value & 1.39 & 0.22 & 1.66 & 0.59 & 3.94 & 0.84 & 1.62 & 0.27 & 2.31 & 0.80 & 3.31 \\
\hline$P$ value & 0.238 & 0.635 & 0.198 & 0.444 & 0.047 & 0.360 & 0.204 & 0.604 & 0.128 & 0.372 & 0.069 \\
\hline Homogeneity $\left(Q_{\mathrm{H}}\right)$ & 408.09 & 51.69 & 29.20 & 33.15 & 253.39 & 15.02 & 37.45 & 11.72 & 368.60 & 51.77 & 14.78 \\
\hline$P$ value & $<0.001$ & $<0.001$ & $<0.001$ & $<0.001$ & $<0.001$ & 0.005 & $<0.001$ & 0.020 & $<0.001$ & $<0.001$ & 0.011 \\
\hline model AIC & 51.93 & - & 21.49 & 51.39 & & 49.86 & & 51.69 & & 51.80 & \\
\hline \multicolumn{12}{|l|}{ Survival } \\
\hline No. of species & 9 & - & - & 6 & 3 & 3 & 6 & 5 & 4 & 4 & 5 \\
\hline Mean effect size $(r)$ & -0.059 & - & - & -0.093 & -0.051 & -0.051 & -0.093 & -0.096 & -0.028 & -0.003 & -0.100 \\
\hline Lower $95 \%$ CI & -0.139 & - & - & -0.186 & -0.108 & -0.108 & -0.186 & -0.197 & -0.081 & -0.045 & -0.177 \\
\hline Upper $95 \%$ CI & 0.022 & - & - & 0.001 & 0.006 & 0.006 & 0.001 & 0.009 & 0.025 & 0.038 & -0.021 \\
\hline$Z$ value & 2.05 & - & - & 3.72 & 3.09 & 3.09 & 3.72 & 3.19 & 1.09 & 0.03 & 6.17 \\
\hline$P$ value & 0.153 & - & - & 0.054 & 0.079 & 0.079 & 0.054 & 0.074 & 0.297 & 0.869 & 0.013 \\
\hline Homogeneity $\left(Q_{\mathrm{H}}\right)$ & 42.01 & - & - & 26.72 & 16.45 & 16.45 & 26.72 & 19.06 & 2.25 & 27.00 & 7.16 \\
\hline$P$ value & $<0.001$ & - & - & $<0.001$ & $<0.001$ & $<0.001$ & $<0.001$ & 0.001 & 0.522 & $<0.001$ & 0.127 \\
\hline Model AIC & 39.34 & - & - & 38.80 & & 38.80 & & 38.49 & & 36.26 & \\
\hline
\end{tabular}

Data set was tested globally, in relation to gender or using sexual dimorphism, colour polymorphism, membership to the Passeriformes order and type of melanin-based traits as moderators. Due to multiple tests, all the reported (uncorrected) $P$ values are considered significant when lower than 0.007 (Bonferonni correction). Positive correlations indicate that the darkest individuals lay eggs earlier in the season, produce more eggs or offspring and have a higher survival, and vice versa for negatives correlations. Significant $Q_{\mathrm{H}}$ indicate that relationship between eumelanin-based coloration and fitness parameter was species-or trait-specific. Significant $P$ values are presented in bold 


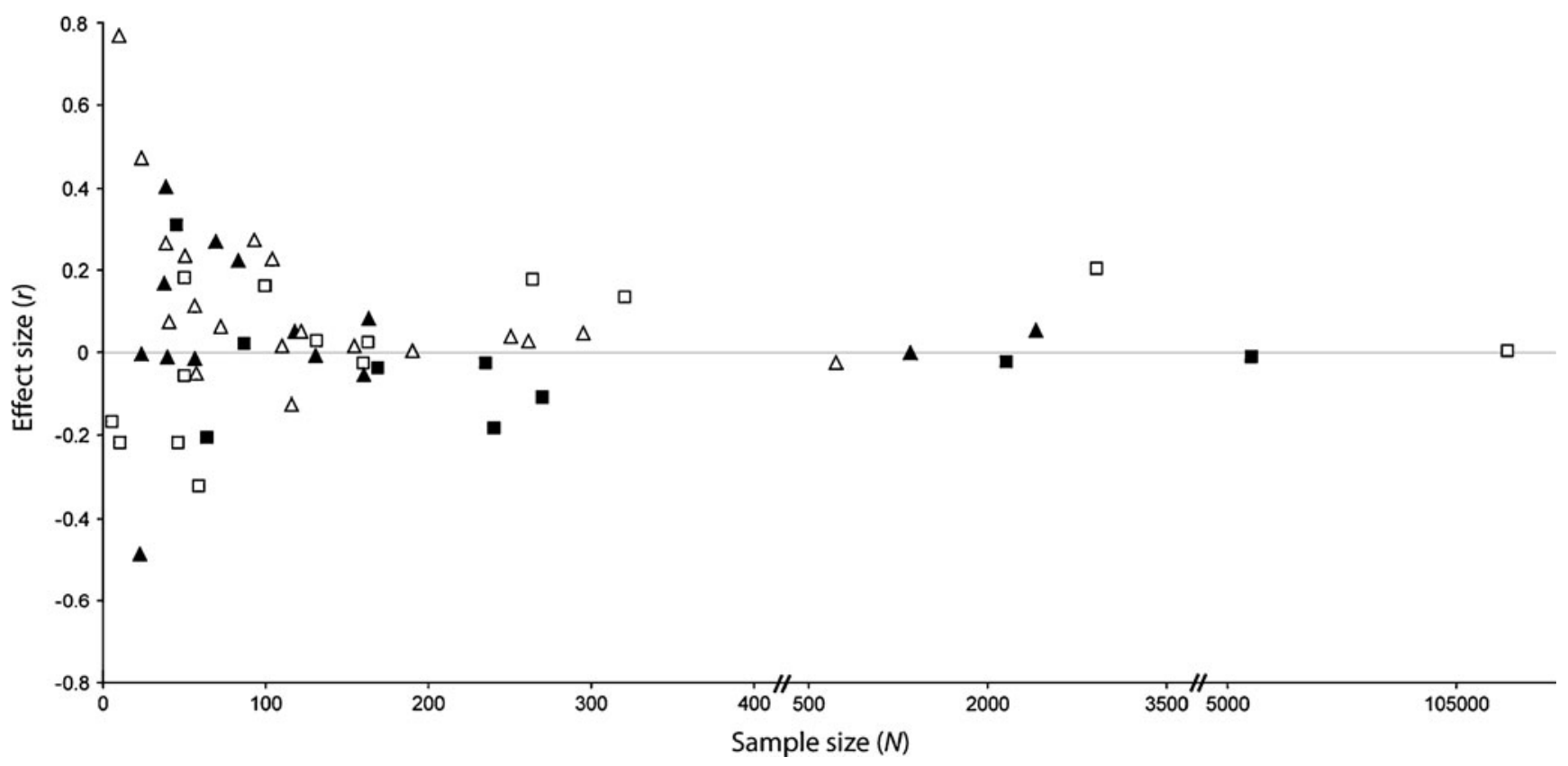

Fig. 1 Relationship between effect size and sample size for studies investigating the relationship between eumelanin-based coloration and brood size (empty triangles), clutch size (filled triangles), laying date

A major goal of our study was to investigate whether a dark or pale melanic coloration reflects individual quality that translates towards a higher reproductive success and/or survival. Our meta-analyses can thus be considered as a first step into understanding how the degree of melaninbased coloration is selected across birds. To evaluate the possibility that the results may depend on the selected species, we performed meta-analyses on non-sexually dimorphic versus sexually dimorphic species (i.e. category of birds in which selection is considered to be directional), in non-passerines versus passerines (i.e. category of birds traditionally considered in the context of sexual selection), in colour monomorphic versus polymorphic species (i.e. a category of birds in which selection is considered to be balanced) and in species in which variation in coloration is due to the size of eumelanic patch versus colour intensity. The finding that across birds, variation in melanin-based coloration was not significantly positively associated with fitness components indicates that across bird species dark individuals have not had a selective advantage over paler conspecifics, or vice versa. Nevertheless, we discovered that in sexually dimorphic species darker individuals achieve a higher reproductive success. This suggests that in species in which members of one sex evolved towards a darker coloration than members of the other sex, a dark coloration signals absolute quality. The same pattern was detected in species for which colour traits vary in size but not in intensity. This finding is important because size of a black patch rather than the density of pigments deposited per unit of body surface signals quality. This proposition (empty squares) and survival (filled squares). Each point corresponds to the mean effect size for both sexes (or one sex if data are missing for the other sex) of one species

should be tackled further and, in particular, researchers should quantify size versus intensity of a colour trait separately. It now remains to investigate the pattern of selection in species in which the expression of melaninbased coloration is condition-dependent. Assuming that a darker coloration is more costly to produce, dark individuals might achieve a higher fitness than pale conspecifics (e.g. Fargallo et al. 2007). Unfortunately, the quantitative genetics of melanin-based coloration has been rarely studied (e.g. Fargallo et al. 2007; Roulin et al. 2010).

Why a dark or pale coloration is not systematically positively selected? Melanin is the most common pigment in animal integuments. Given that melanin plays key physical and biological protective roles and that in some species melanin-based ornaments signal absolute individual quality due to the cost entailed by their production (Fitze and Richner 2002; Fargallo et al. 2007) and sensitivity to environmental factors (Jensen et al. 2003), we could have predicted that across birds the darkest version of a colour trait is favoured under natural or sexual selection. At least two mechanisms can explain why lighter coloured individuals are positively selected in some species while in other species the darkest individuals have a selective advantage. First, camouflage may be best achieved with a light or dark coloration in different species (e.g. Götmark 1987; Hoekstra et al. 2005). The situation might be complex as natural selection can favour a drab plumage to enhance cryptism, while sexual selection might select for the most conspicuous individuals as a signal of the ability to avoid predators (Götmark 1993). Comparative analyses should be carried out 
to identify the ecological factors associated with the evolution of dark and pale melanic plumage. Second, genes involved in melanogenesis can pleiotropically regulate many physiological and behavioural functions in a complex way (Ducrest et al. 2008). The cost/benefit balance of these multiple pleiotropic effects probably differ between species, implying that different degrees of melanin-based coloration may be indirectly selected in different species. There might be situations where the pleiotropic effects of genes involved in melanogenesis are beneficial but other situations where they entail costs. For instance, the melanocortin system triggers the production of eumelanin pigments but has also immunostimulatory effects (Ducrest et al. 2008). Given the costs of immunity (Bonneaud et al. 2003) the optimal level of immunity may differ between populations or species implying that parasites may indirectly select for different degrees of melanin-based coloration.

For these three reasons, our results showing that sign and magnitude of selection exerted on melanic coloration differs between species is not so surprising. The absence of a general pattern of selection on melanin-based coloration is particularly stimulating to identify the ecological factors that make species or colour traits so different. For instance, detailed observations in the cosmopolitan barn owl showed that different degrees of melanin-based coloration are selected in different parts of the world (Roulin et al. 2009; Antoniazza et al. 2010). This suggests that selection can either favour dark or pale colour traits depending on ecological factors. Furthermore, in some species individuals become darker with age (Potti and Montalvo 1991) and lighter coloured in other species (Anderson et al. 2009). In raptors, FergusonLees and Christie (2001) reported 110 species out of 315 (35\%) for which some parts of the plumage become lighter coloured with age and 222 species out of $317(70 \%)$ for which the plumage becomes darker with age. Although darkening is more prevalent than whitening, it seems that in a non-negligible number of species a light melanic plumage is favoured over a dark plumage.

Acknowledgements The Swiss National Science Foundation financed the study (grant no. 3100AO_120517 to A. R.). We thank Dean Adams for providing support on the methods of phylogenetic meta-analysis, Marie-Amélie Girardet for screening the book of Ferguson-Lees and Christie (2001) to count raptorial species that darken or whiten with age, and Nicolas Salamin, Tim Parker, Kevin McGraw and three anonymous referees for comments on the manuscript.

\section{References}

Alström P, Ericson PGP, Olsson U, Sundberg P (2006) Phylogeny and classification of the avian superfamily Sylvioidea. Mol Phyl Evol 38:381-297

Amat JA (2005) Does the expression of a male plumage trait in female Kentish plovers (Charadrius alexandrinus) signal individual quality? J Ornithol 146:287-290
Anderson TM, vonHoldt BM, Candille SI, Musiani M, Greco C, Stahler DR, Smith DW, Padhukasahasram B, Randi E, Leonard JA, Bustamante CD, Ostrander EA, Tang H, Wayne RK, Barsh GS (2009) Molecular and evolutionary history of melanism in North American gray wolves. Science 323:1339-1343

Antoniazza S, Burri R, Fumagalli L, Goudet J, Roulin A (2010) Local adaptation maintains clinal variation in melanin-based coloration of European barn owls (Tyto alba). Evolution 64:1944-1954

Bize P, Gasparini J, Klopfenstein A, Altwegg R, Roulin A (2006) Melanin-based coloration is a nondirectionally selected sexspecific signal of offspring development in the Alpine Swift. Evolution 60:2370-2380

Bókony V, Liker A, Lendvai AZ, Kulcsár A (2008) Risk-taking and survival in the house sparrow Passer domesticus: are plumage ornaments costly? Ibis 150:139-151

Bond AB, Kamil AC (1998) Apostatic selection by blue jays produces balanced polymorphism in virtual prey. Nature 395:594-596

Bonneaud C, Mazuc J, Gonzalez G, Haussy C, Chastel O, Sorci G (2003) Assessing the cost of mounting an immune response. Am Nat 161:367-379

Bonser RHC (1995) Melanin and the abrasion resistance of feathers. Condor 97:590-591

Borenstein M, Hedges LV, Higgins JPT, Rothstein HR (2009) Introduction to meta-analysis. John Wiley \& Sons, Ltd, Chichester

Bortolotti GR, Blas J, Negro JJ, Tella JL (2006) A complex plumage pattern as an honest social signal. Anim Behav 72:423-430

Brommer JE, Ahola K, Karstinen T (2005) The colour of fitness: plumage coloration and lifetime reproductive success in the tawny owl. Proc R Soc Lond B Biol Sci 272:935-940

Brown JW, Payne RB, Mindell DP (2007) Comment. Nuclear DNA does not reconcile 'rocks' and 'clocks' in Neoaves: a comment on Ericson et al. Biol Lett 3:257-259

Buchanan KL, Evans MR, Goldsmith AR, Bryant DM, Rowe LV (2001) Testosterone influences basal metabolic rate in male house sparrows: a new cost of dominance signalling? Proc R Soc Lond B Biol Sci 268:1337-1344

Burtt EH (1979) Tips on wings and other things. In: Burtt EH (ed) The behavioural significance of color. Garland STPM Press, New York, pp 75-100

Chakarov N, Boerner M, Krüger O (2008) Fitness in common buzzards at the cross-point of opposite melanin-parasite interactions. Funct Ecol 22:1062-1069

Childress RB, Bennun LA (2002) Sexual character intensity and its relationship to breeding timing, fecundity and mate choice in the great cormorant Phalacrocorax carbo lucidus. J Avian Biol 33:23-30

Clusella Trullas S, van Wyk JH, Spotila JR (2007) Thermal melanism in ectotherms. J Therm Biol 32:235-245

Cooch G (1961) Ecological aspects of the blue-snow goose complex. Auk 78:72-89

Cooke F, Findlay CS, Rockwell RF, Smith JA (1985) Life history studies of the lesser snow goose (Anser caerulescens caerulescens): III. The selective value of plumage polymorphism: net fecundity. Evolution 39:165-177

Cooke F, Rockwell RF, Lank DB (1995) The snow geese of La Pérouse Bay, natural selection in the wild. Oxford University Press, Oxford

Dale J (2000) Ornamental plumage does not signal male quality in red-billed queleas. Proc R Soc Lond B Biol Sci 267:2143-2149

Davis JWF (1976) Breeding success and experience in the Arctic skua, Stercorarius parasiticus (L.). J Anim Ecol 45:531-535

Doucet SM, Mennill DJ, Montgomerie R, Boag PT, Ratcliffe LM (2005) Achromatic plumage reflectance predicts reproductive success in male black-capped chickadees. Behav Ecol 16:218-222

Ducrest A-L, Keller L, Roulin A (2008) Pleiotropy in the melanocortin system, coloration and behavioural syndromes. Trends Ecol Evol 23:502-510 
Ericson P, Anderson C, Britton T, Elzanowski A, Johansson U, Källersjö M, Ohlson J, Parsons T, Zuccon D, Mayr G (2006) Diversification of Neoaves: integration of molecular sequence data and fossils. Biol Lett 2:543-547

Fain MG, Houde P (2004) Parallel Radiations in the primary clades of birds. Evolution 58:2558-2573

Fargallo JA, Laaksonen T, Korpimäki E, Wakamatsu K (2007) A melanin-based trait reflects environmental growth conditions of nestling male Eurasian kestrels. Evol Ecol 21:157-171

Ferguson-Lees J, Christie DA (2001) Raptors of the world. Helm Identification Guides, London

Fitze PS, Richner H (2002) Differential effects of a parasite on ornamental structures based on melanins and carotenoids. Behav Ecol 13:401-407

Galeotti P, Sacchi R (2003) Differential parasitaemia in the tawny owl (Strix aluco): effects of colour morph and habitat. J Zool 261:9199

Galván I, Alonso-Alvarez C (2008) An intracellular antioxidant determines the expression of a melanin-based signal in a bird. PLoS Biol 3:e3335

Gasparini J, Bize P, Piault R, Kazumasa W, Blount J, Roulin A (2009) Strength and cost of mounting an immune response are associated with a heritable melanin-based color trait in female tawny owls. J Anim Ecol 78:608-616

Götmark F (1987) White underparts in gull function as hunting camouflage. Anim Behav 35:1786-1792

Götmark F (1993) Conspicuous coloration in male birds is favoured by predation in some species and disfavoured in others. Proc R Soc Lond B Biol Sci 253:143-146

Grant BR (1990) The significance of subadult plumage in Darwin's finches, Geospiza fortis. Behav Ecol 1:161-170

Grant BR, Grant PR (1987) Mate choice in Darwin's finches. Biol J Linn Soc 32:247-270

Griffith SC (2000) A trade-off between reproduction and a conditiondependent sexually selected ornament in the house sparrow Passer domesticus. Proc R Soc Lond B Biol Sci 267:1115-1119

Griffith SC, Owens IPF, Burke T (1999) Female choice and annual reproductive success favour less-ornamented male house sparrows. Proc R Soc Lond B Biol Sci 266:765-770

Hackett SJ, Kimball RT, Reddy S, Bowie RCK, Braun EL, Braun MJ, Chojnowski JL, Cox WA, Han K-L, Harshman J, Huddleston CJ, Marks BD, Miglia KJ, Moore WS, Sheldon FH, Steadman DW, Witt CC, Yuri T (2008) A phylogenomic study of birds reveals their evolutionary history. Science 320:1763-1768

Hanssen SV, Folstad I, Erikstad KE (2006) White plumage reflects individual quality in female eiders. Anim Behav 71:337-343

Hanssen SA, Hasselquist D, Folstad I, Erikstad KE (2008) A label of health: a previous immune challenge is reflected in the expression of a female plumage trait. Biol Lett 4:379-381

Hatch SA (1991) Evidence for color phase effects on the breeding and life history of northern fulmars. Condor 93:4090-4417

Hoekstra HE, Krenz JG, Nachman MW (2005) Local adaptation in the rock pocket mouse (Chaetodipus intermedius): natural selection and phylogenetic history of populations. Heredity 94:217-228

Horth L (2003) Melanic body colour and aggressive mating behaviour are correlated traits in male mosquitofish (Gambusia holbrooki). Proc R Soc Lond B Biol Sci 266270:1033-1040

Hughes JM, Lange CL, Mather PB, Robinson A (2002) A comparison of fitness components among different plumage morphs of the Australian Magpie. Gymnorhina tibicen Emu 102:331-338

Järvi T, Røskaft E, Bakken M, Zumsteg B (1987) Evolution of variation in male secondary sexual characteristics. A test of eight hypotheses applied to pied flycatchers. Behav Ecol Sociobiol 20:161-169

Jawor JM, Breitwisch R (2003) Melanin ornaments, honesty, and sexual selection. Auk 120:249-265
Jensen H, Sæther BE, Ringsby TH, Tufto J, Griffith SC, Ellegren H (2003) Sexual variation in heritability and genetic correlations of morphological traits in house sparrow (Passer domesticus). J Evol Biol 16:1296-1307

Jensen H, Sæther BE, Ringsby TH, Tufto J, Griffith SC, Ellegren H (2004) Lifetime reproductive success in relation to morphology in the house sparrow Passer domesticus. J Anim Ecol 73:599611

Johannesson K, Ekendahl A (2002) Selective predation favouring cryptic individuals of marine snails (Littorina). Biol J Linn Soc 76:137-144

Johansson US, Fjeldså J, Bowie RCK (2008) Phylogenetic relationships within Passerida (Aves: Passeriformes): a review and a new molecular phlogeny based on three nuclear intron marklers. Mol Phyl Evol 48:858-876

Jones JS, Leith BH, Rawlings P (1977) Polymorphism in Cepaea: a problem with too many solutions ? Annu Rev Ecol Syst 8:109143

Kimball RT, Braun EL (2008) A multigene phylogeny of Galliformes supports a single origin of erectile ability in non-feathered facial traits. J Avian Biol 39:438-445

Kingma S, Szentirmai I, Székely T, Bókony V, Bleeker M, Liker A, Komdeur J (2008) Sexual selection and the function of a melanin-based plumage ornament in polygamous penduline tits Remiz pendulinus. Behav Ecol Sociobiol 62:1277-1288

Kristín A, Valera F, Hoi C, Hoi H (2007) Do melanin-based tail patterns predict individual quality and sex in Lesser Grey Shrikes Lanius minor ? J Ornithol 148:1-8

Lajeunesse MJ (2009) Meta-analysis and the comparative phylogenetic method. Am Nat 174:369-381

Lemon RE, Weary DM, Norris KJ (1992) Male morphology and behavior correlate with reproductive success in the American redstart (Setophaga ruticilla). Behav Ecol Sociobiol 29:399-403

Lendvai AZ, Liker A (2004) Male badge size is related to clutch volume in the Kentish plover. Ornis Hung 14:1-7

Losey JE, Uves AR, Harmon J, Ballantyne F, Brown C (1997) A polymorphism maintaine by opposite patterns of parasitism and predation. Nature 388:269-272

Lovette IJ, Bermingham E (2002) What is a wood-warbler? Molecular characterization of a monophyletic Parulidae. Auk 119:695-714

Maddison WP, Maddison DR (2009) Mesquite: a modular system for evolutionary analysis. Version $2.6 \mathrm{http} / / /$ mesquiteproject.org

McGraw KJ (2005) The antioxidant function of many animal pigments: are there consistent health benefits of sexually selected colourants? Anim Behav 69:757-764

McGraw KJ, Hill GE (2000) Differential effects of endoparasitism on the expression of carotenoid- and melanin-based ornamental coloration. Proc R Soc Lond B Biol Sci 267:1525-1531

McGraw KJ, Mackillop EA, Dale J, Hauber ME (2002) Different colors reveal different information: how nutritional stress affects the expression of melanin- and structurally based ornamental plumage. J Exp Biol 205:3747-3755

McKinnon EA, Robertson RJ (2008) The signal function of a melanin-based plumage ornament in golden-winged warblers. Wilson J Ornithol 120:366-370

Mackintosh JA (2001) The antimicrobial properties of melanocytes, melanosomes and melanin and the evolution of black skin. J Theor Biol 212:101-128

Møller A, Flensted-Jensen E, Mardal W (2007) Black beak tip coloration as a signal of phenotypic quality in a migratory seabird. Behav Ecol Sociobiol 61:1561-1571

Møller A, Jennions M (2002) How much variance can be explained by ecologists and evolutionary biologists? Oecologia 132:492-500

Møller AP, Jennions MD (2001) Testing and adjusting for publication bias. Trends Ecol Evol 16:580-586 
Mundy NI, Badcock NS, Hart T, Scribner K, Janssen K, Nadeau NJ (2004) Conserved genetic basis of a quantitative plumage trait involved in mate choice. Science 303:1870-1873

Nakagawa S, Ockendon N, Gillespie DOS, Hatchwell BJ, Burke T (2007) Assessing the function of house sparrows' bib size using a flexible meta-analysis method. Behav Ecol 18:831-840

Norris KJ (1990) Female choice and the evolution of the conspicuous plumage coloration of monogamous male great tits. Behav Ecol Sociobiol 26:129-138

O'Donald P (1983) The arctic skua. Cambridge University Press, Cambridge

Paradis E, Claude J, Strimmer K (2004) APE: analysis of phylogenetics and evolution in $\mathrm{R}$ language Bioinformatics. Bioinformatics 20:289-290

Philips RA, Furness RW (1998) Polymorphism, mating preferences and sexual selection in the Arctic skua. J Zool Lond 245:245252

Potti J, Montalvo S (1991) Male colour variation in Spanish pied flycatchers Ficedula hypoleuca. Ibis 133:293-299

R Development Core Team (2009) R: a language and environment for statistical computing

Rice WR, Gaines SD (1994a) Extending nondirectional heterogeneity tests to evaluate simply ordered alterntive hypotheses. Proc Natl Acad Sci USA 91:225-226

Rice WR, Gaines SD (1994b) The ordered-heterogeneity family of tests. Biometrics 50:746-746

Rockwell RF, Scott Findlay C, Cooke F, Smith JA (1985) Life history studies of the Lesser Snow Goose (Anser caerulescens caerulescens): IV. The selective value of plumage polymorphism: net viability, the timing of maturation, and breeding propensity. Evolution 39:178-189

Rosenberg MS (2005) The file-drawer problem revisited: a general weighted method for calculating fail-safe numbers in metaanalysis. Evolution 59:464-468

Rosenberg MS, Adams DC, Gurevith J (2000) MetaWin: statistical software for meta-analysis. Sinauer Associates, Sunderland

Rosenthal R (1991) Meta-analytic procedures for social research. Applied Social Research Methods. Sage Publications, Newbury

Roulin A (2004) The evolution, maintenance and adaptive function of genetic colour polymorphism in birds. Biol Rev 79:815-848

Roulin A, Altwegg R (2007) Breeding rate is associated with pheomelanism in male and with eumelanism in female barn owls. Behav Ecol 18:563-570

Roulin A, Richner H, Ducrest A-L (1998) Genetic, environmental and condition-dependent effects on female and male plumage ornamentation. Evolution 52:1451-1460

Roulin A, Ducrest A-L, Ravussin P-A, Altwegg R (2003) Female plumage coloration covaries with reproductive strategies in the tawny owl. J Avian Biol 34:251-258

Roulin A, Wink M (2004) Predator-prey polymorphism: relationships and the evolution of colour a comparative analysis in diurnal raptors. Biol J Linn Soc 81:565-578
Roulin A, Almais B, Rossi-Pedruzzi A, Ducrest A-L, Wakamatsu K, Miksik I, Blount JD, Jenni-Eiermann S, Jenni L (2008) Corticosterone mediates the condition-dependent component of melanin-based coloration. Anim Behav 75:1351-1358

Roulin A, Wink M, Salamin N (2009) Selection on a eumelanic ornament is stronger in the tropics than in temperate zones in the worldwide-distributed barn owl. J Evol Biol 22:345-354

Roulin A, Altwegg R, Jensen H, Steinsland I, Schaub M (2010) Sexdependent selection on an autosomal melanic female ornament promotes the evolution of sex ratio bias. Ecol Lett 13:616-626

Sanderson MJ (2002) Estimating absolute rates of molecular evolution and divergence times: a penalized likelihood approach. Mol Biol Evol 19:101-109

Schroeder J, Lourenço P, van der Velde M, Hooijmeijer J, Both C, Piersma T (2009) A possible case of contemporary selection leading to a decrease in sexual plumage dimorphism in a grassland-breeding shorebird. Behav Ecol 20:797-807

Sheldon BC, West SA (2004) Maternal dominance, maternal condition, and offspring sex ratio in ungulate mammals. Am Nat 163:40-54

Siefferman L, Hill GE (2005) Evidence for sexual selection on strucutral plumage coloration in female Eastern Bluebirds (Sialia sialis). Evolution 59:1819-1828

Sokal RR, Rohlf FJ (1995) BIOMETRY: The principles and practice of statistics in biological research. W. H. Freeman and Company, New York

Swofford DL (2003) PAUP*: Phylogenetic analysis using parsimony (*and other methods). Version 4. Sinauer Associates, Sunderland

Tella JL, Forero MG, Donazar JA, Hiraldo F (1997) Is the expression of male traits in female lesser kestrels related to sexual selection? Ethology 103:72-81

Thompson JD, Higgins DG, Gibson TJ (1994) CLUSTAL W: improving the sensitivity of progressive multiple sequence alignment through sequence weighting, position-specific gap penalties and weight matrix choice. Nucleic Acids Res 22:4673-4680

Thusius KJ, Peterson KA, Dunn PO, Whittingham LA (2001) Male mask size is correlated with mating success in the common yellowthroat. Anim Behav 62:435-446

Treplin S, Siegert R, Bleidorn C, Thompson HS, Fotso R, Tiedemann R (2008) Molecular phylogeny of songbirds (Aves: Passeriformes) and the relative utility of common nuclear marker loci. Cladistics 24:328-349

Vaclav R, Hoi H (2002) Different reproductive tactics in house sparrows signalled by badge size: is there a benefit to being average? Ethology 108:569-582

Vergara P, Fargallo JA, Martínez-Padilla J, Lemus JA (2009) Inter-annual variation and information content of melanin-based coloration in female Eurasian kestrels. Biol J Linn Soc 97:781-790

West SA, Shuker DM, Sheldon BC (2005) Sex-ratio adjustment when relatives interact: a test of constraints on adaptation. Evolution 59:1211-1228 